Abstract 01-S05.01 Table 1 Associations between prevalence of BV candidate organisms and lifetime sexual partners

\begin{tabular}{|c|c|c|c|c|c|c|c|c|c|}
\hline $\begin{array}{l}\text { Candidate } \\
\text { organism }\end{array}$ & $\begin{array}{l}\text { Megasphaera spp. } \\
\text { detected } \\
\text { (prevalence \%) }\end{array}$ & $\begin{array}{l}\text { Sneathia spp. } \\
\text { prevalence } \\
\text { detected } \\
\text { (prevalence \%) }\end{array}$ & $\begin{array}{l}\text { Leptotrichia spp. } \\
\text { detected } \\
\text { (prevalence \%) }\end{array}$ & $\begin{array}{l}\text { L crispatus } \\
\text { prevalence } \\
\text { detected } \\
\text { (prevalence \%) }\end{array}$ & $\begin{array}{l}\text { G vaginalis } \\
\text { prevalence } \\
\text { detected } \\
\text { (prevalence \%) }\end{array}$ & $\begin{array}{l}\text { BVAB1 } \\
\text { prevalence } \\
\text { detected } \\
\text { (prevalence \%) }\end{array}$ & $\begin{array}{l}\text { BVAB2 } \\
\text { prevalence } \\
\text { detected } \\
\text { (prevalence \%) }\end{array}$ & $\begin{array}{l}\text { BVAB3 } \\
\text { prevalence } \\
\text { detected } \\
\text { (prevalence \%) }\end{array}$ & $\begin{array}{l}\text { A vaginae } \\
\text { prevalence } \\
\text { detected } \\
\text { (prevalence \%) }\end{array}$ \\
\hline \multicolumn{10}{|c|}{ Women with normal flora } \\
\hline \multicolumn{10}{|c|}{ Lifetime sexual partners } \\
\hline 0 & $2 / 79(3)$ & $3 / 79(4)$ & $3 / 79(4)$ & $45 / 79(57)$ & $24 / 79(30)$ & $0 / 79$ & $0 / 79(0)$ & $0 / 79$ & $53 / 79(67)$ \\
\hline $1-10$ & $1 / 82(1)$ & $4 / 82(5)$ & $3 / 82(4)$ & $60 / 82(73)$ & $41 / 82(50)$ & $0 / 82$ & $6 / 82(7)$ & $0 / 82$ & $56 / 82(68)$ \\
\hline$>10$ & $6 / 72(8)$ & $10 / 72(14)$ & $12 / 72(17)$ & $59 / 72(82)$ & $49 / 72(68)$ & $0 / 72$ & $6 / 72(8)$ & $2 / 72(3)$ & $34 / 72(48)$ \\
\hline $\mathrm{p}$ for trend & 0.1 & 0.03 & 0.006 & 0.001 & $<0.001$ & Undefined & 0.2 & 0.2 & 0.02 \\
\hline \multicolumn{10}{|c|}{ Women with BV } \\
\hline \multicolumn{10}{|c|}{ Lifetime sexual partners } \\
\hline 0 & $1 / 3(33)$ & $1 / 3(33)$ & $1 / 3(33)$ & $1 / 3(33)$ & $3 / 3(100)$ & $0 / 3(0)$ & $0 / 3(0)$ & $0 / 3(0)$ & $2 / 3(67)$ \\
\hline $1-10$ & $12 / 33(36)$ & $17 / 33(52)$ & $16 / 33(49)$ & $11 / 33(33)$ & $31 / 33(94)$ & $1 / 33(3)$ & 18/33 (55) & $4 / 33(12)$ & $33 / 33(100)$ \\
\hline$>10$ & $12 / 69(17)$ & $60 / 69(87)$ & $59 / 69(86)$ & $35 / 69(51)$ & $69 / 69(100)$ & $6 / 69(9)$ & $54 / 69(78)$ & $13 / 69(19)$ & $67 / 67(100)$ \\
\hline$p$ for trend & 0.07 & $<0.001$ & $<0.001$ & 0.2 & 0.3 & 0.3 & 0.004 & 0.3 & 0.04 \\
\hline
\end{tabular}

were scored by the Nugent method. Three-hundred-and-thirty-nine samples from women with normal flora and BV were selected for analysis using quantitative PCR assays (qPCR) targeting the specific 16S rRNA gene sequences of eight published COs ( $G$ vaginalis, $A$ vaginae, Megasphaera spp., Sneathia spp., BVAB1, BVAB2, BVAB3, and Leptotrichia spp.) and $L$ crispatus. Detection of COs and $L$ crispatus and their total bacterial loads were compared between women with BV and normal flora. The associations between prevalence of COs and specific sexual behavioural practices were examined by univariate and multivariate analysis.

Results Analysis found all COs were strongly associated with BV compared with normal flora and $L$ crispatus was negatively associated. $G$ vaginalis and $A$ vaginae were relatively common in sexually inexperienced women: however other COs were absent in a truly virginal population. When women with normal flora and BV were analysed separately, Sneathia spp., BVAB1, BVAB2, BVAB3, Leptotrichia spp. and $G$ vaginalis all demonstrated a progressive increase in prevalence with increasing sexual experienced and increasing numbers of vaginal sexual partners see Abstract O1-S05.01 table 1. Megasphaera spp. however differed from other COs, with a higher prevalence being strongly associated with increasing oral sex frequency and oral sex partner number.

Conclusions These data provide compelling evidence for sexual transmission of several COs-with absence of COs in virginal women and increasing prevalence with increasing sexual exposure. Interestingly the COs Sneathia spp., BVAB1, BVAB2, BVAB3, Leptotrichia spp. and $G$ vaginalis are significantly associated with vaginal sex while the epidemiological association of Megasphaera spp. differed from the other COs being significantly associated with oral sex.

\section{1-S05.02 BIOLOGICAL EVIDENCE OF SEMEN EXPOSURE IS ASSOCIATED WITH INCIDENT BACTERIAL VAGINOSIS}

doi:10.1136/sextrans-2011-050109.26

${ }^{1} \mathrm{M}$ Gallo, ${ }^{1} \mathrm{~L}$ Warner, ${ }^{1} \mathrm{C}$ King, ${ }^{2} \mathrm{~J}$ Sobel, ${ }^{3} \mathrm{~A}$ Rompalo, ${ }^{4} \mathrm{~S}$ Cu-Uvin, ${ }^{5} \mathrm{R}$ Klein, ${ }^{6} \mathrm{E}$ Schoenbaum, ${ }^{1} \mathrm{D}$ Jamieson. ${ }^{1}$ Centers for Disease Control and Prevention, Atlanta, USA; ${ }^{2}$ Wayne State University School of Medicine, Detroit, USA; ${ }^{3}$ Johns Hopkins University School of Medicine, Baltimore, USA; ${ }^{4}$ Brown University School of Medicine, Providence, USA; ${ }^{5}$ Mount Sinai School of Medicine, New York, USA; ${ }^{6}$ Albert Einstein College of Medicine, USA

Objectives (1) To identify correlates of incident Bacterial vaginosis (BV) among high-risk women and (2) to identify predictors of discordance between self-reported lack of semen exposure in the past 6 months and the detection of spermatozoa on Gram stain, which provides biological evidence of recent exposure.

Methods Analyses were based on among 871 HIV-infected and 439 HIV-uninfected women participating in HIV Epidemiology
Research Study (HERS) which was conducted in 4 sites in the US Participants completed study visits conducted at baseline and at 6 month intervals thereafter. We conducted both cohort and casecrossover analyses, stratified by HIV infection status, to evaluate potential correlates of incident BV. We also used logistic regression to identify predictors of discordance between self-reported lack of exposure to semen and the detection of spermatozoa on Gram stain. Results BV incidence was 21\% among HIV-infected women and $19 \%$ among HIV-uninfected women. We found fewer correlates of incident BV when assessed with a case-crossover design than with a cohort design. Reporting frequent coitus (regardless of consistency of condom use) was correlated with incident BV in the cohort analyses but not in the case-crossover analyses. The sole correlate that emerged in both the cohort and case-crossover analyses among HIV-infected and -uninfected women was the detection of spermatozoa on Gram stain. Seven factors were associated with discordance between self-reported semen exposure and spermatozoa detection in the multivariable analysis. Discordance differed by study site and race/ethnicity and was more common among younger women. The following infections or conditions also were predictive of discordance: HIV (adjusted OR [aOR], 2.8; 95\% CI, $1.7 \%$ to $4.6 \%$ ), $\mathrm{BV}$ (aOR, $1.9 ; 95 \% \mathrm{CI}, 1.5 \%$ to $2.5 \%$ ), and human papillomavirus (aOR, 1.3; 95\% CI, 1.0\% to 1.8\%). Finally, reporting current injection drug use (aOR, 0.6; $95 \% \mathrm{CI}, 0.4 \%$ to $0.9 \%$ ) was inversely related to discordance.

Conclusions The inconsistent association between condom use and $\mathrm{BV}$ found in prior studies could be the result of participant reporting bias. The present study found evidence of a relationship between semen exposure and incident BV. Also, given the number and range of correlates of discordance between self-reported and biological evidence of semen exposure, inaccuracies in the reporting of sexual behaviours cannot be assumed to be distributed randomly across a study population.

\section{1-S05.03 BEHAVIOURAL FACTORS ASSOCIATED WITH BACTERIAL VAGINOSIS (BV) IN WOMEN WHO HAVE SEX WITH WOMEN (WSW): THE WOMEN ON WOMEN'S (WOW) HEALTH STUDY}

doi:10.1136/sextrans-2011-050109.27

${ }^{1} \mathrm{C}$ Bradshaw, ${ }^{2} \mathrm{~J}$ Bilardi, ${ }^{2} \mathrm{~S}$ Walker, ${ }^{2} \mathrm{~L}$ Vodstrcil, ${ }^{3} \mathrm{~S}$ Garland, ${ }^{2} \mathrm{~J}$ Hocking, ${ }^{4} \mathrm{M}$ Chen, ${ }^{4} \mathrm{~S}$ Peterson, ${ }^{4} \mathrm{G}$ Fehler, ${ }^{2} \mathrm{C}$ Fairley. ${ }^{1}$ Melbourne Sexual Health Centre, University of Melbourne, Melbourne, Australia; ${ }^{2}$ University of Melbourne, Melbourne, Australia; ${ }^{3}$ Royal Womens Hospital, Australia; ${ }^{4}$ Melbourne sexual health centre, Austria

Background We are conducting a national 2 year cohort study in 400 Australian WSW to determine the behavioural and microbiological 
factors associated with prevalent and incident BV in women and their sexual partners. Data from the cross-sectional study will be presented.

Methods WSW were recruited using internet, festival and mediabased promotion and were ineligible if they are postmenopausal, pregnant or had not had a female sex partner (FSP) in the last 18 months. Study-kits containing consent forms, questionnaires, swabs and slides were sent to participants and returned by post. At baseline, women self-collected three consecutive vaginal swabs and slides at weekly intervals and completed detailed demographic behavioural data via an online or paper-based questionnaire. Gramstained self-collected vaginal smears (SCVS) were scored by the Nugent method. Women were classified as having prevalent BV if $\geq 1$ slides had a Nugent score (NS) of 7-10, intermediate flora if $\geq 1$ slides had a NS $=4-6$ and normal flora if all three slides had a $\mathrm{NS}=0-3$. Univariate and multivariate analyses were performed using SPSS to examine the association between BV and behavioural practices.

Results In February 2011, 342 (86\%) women had been recruited and 314 (92\%) women had completed all cross-sectional requirements. Median age was 31 years (range 19-49), 309 (98\%) reported a FSP in the last year, 253 (81\%) had a current sexual partner ( $95 \%$ female) and $246(78 \%)$ reported vaginal sex with a male in the past. The prevalence of BV was $29 \%$ ( $95 \%$ CI $20 \%$ to $38 \%$ ) in women providing $\geq 1$ SCVS. Two hundred and seventy-five (88\%) women provided all three SCVS of which 178 (65\%) had stable normal flora on all slides, $56(20 \%)$ stable BV and $41(15 \%)$ had unstable flora transitioning between $\geq 1$ Nugent categories over the three slides. Multivariate analysis found that being a current smoker of cigarettes or marijuana (Adjusted OR AOR $=2.2 ; 95 \% \mathrm{CI}: 1.3 \%$ to $3.8 \%$ ) and having $>5$ lifetime FSPs (AOR $=1.8 ; 1.0$ to 3.01 ) was significantly associated with prevalent BV. A borderline association with FSP receptive oral sex $(A O R=3.2 ; 0.9$ to 11.0$)$ was evident. $B V$ was not associated with increased age or numbers of male partners.

Conclusion Prevalent BV is common (30\%) in WSW and is strongly associated with smoking and increasing numbers of FSPs but not male partners. A high proportion of WSW had stable vaginal flora $(85 \%)$ over a 3 week period. This study aims to advance our understanding of epidemiology of BV in WSW.

\section{1-S05.04 INCREASED RISK FOR TRICHOMONAS VAGINALIS IN AN URBAN POPULATION OF YOUNG ADULTS}

doi:10.1136/sextrans-2011-050109.28

${ }^{1} \mathrm{~S}$ Rogers, ${ }^{2} \mathrm{C}$ Turner, ${ }^{3} \mathrm{~W}$ Miller, ${ }^{4} \mathrm{~A}$ Roman, ${ }^{3} \mathrm{M}$ Hobbs, ${ }^{1} \mathrm{~S}$ Tan. ${ }^{1}$ Research Triangle Institute, Washington, USA; ${ }^{2}$ City University of New York Flushing, USA; ${ }^{3}$ University of North Carolina, Chapel Hill, USA; ${ }^{4}$ University of Massachusetts, Boston, USA

Background The epidemiology of $T$ vaginalis (TV) in the general population is not well understood, although it is reported to be the most common curable sexually transmitted infection worldwide. Surveillance data do not exist either for US national or local populations. Infection with TV increases the likelihood of HIV acquisition and has been associated with adverse health outcomes in men and women.

Methods The Monitoring STIs Survey Program (MSSP) used telephone audio computer-assisted self-interview technology and specimen collection kits sent out and returned by mail to monitor $T$ vaginalis and $C$ trachomatis among a probability sample of 15 to 35 year-olds residing in Baltimore, MD from September 2006 through June 2009. Specimens were tested using TMA-based APTIMA assays. Weighted estimates of infection prevalence by respondents' sociodemographic and behavioural characteristics were tabulated using poisson regression.
Abstract 01-S05.04 Table 1 Estimated prevalence of trichomoniasis and chlamydial infection by respondent characteristics: monitoring STIs in the population, 2006-09

\begin{tabular}{|c|c|c|c|c|c|}
\hline Characteristic & $\mathbf{N}$ & $\begin{array}{l}\boldsymbol{T} \text { vaginalis } \\
\text { Wtd.\% }(95 \% \mathrm{CI})\end{array}$ & p & $\begin{array}{l}\text { C trachomatis } \\
\text { Wtd.\% (95\% Cl) }\end{array}$ & $\mathbf{p}$ \\
\hline Total & 2120 & $7.5(6.0$ to 9.0$)$ & & $3.9(2.7$ to 5.0$)$ & \\
\hline \multicolumn{6}{|l|}{ Sex } \\
\hline Women & 1322 & $11.8(9.6$ to 14.3$)$ & & $3.4(2.4$ to 4.8$)$ & \\
\hline Men & 798 & 2.9 (1.6 to 5.1$)$ & $<0.001$ & 4.5 (2.8 to 7.0$)$ & 0.35 \\
\hline \multicolumn{6}{|l|}{ Race } \\
\hline Black & 1299 & $11.2(9.1$ to 13.6$)$ & & $6.0(4.4$ to 8.1$)$ & \\
\hline Non-black & 821 & $2.0(1.2$ to 3.5$)$ & $<0.001$ & $0.7(0.2$ to 2.0$)$ & $<0.001$ \\
\hline \multicolumn{6}{|l|}{ Age } \\
\hline $15-19$ & 576 & 7.3 (4.7 to 11.2 ) & & $6.6(4.2$ to 10.5$)$ & \\
\hline $20-24$ & 460 & $10.6(7.6$ to 14.7$)$ & & 5.9 (3.6 to 9.7$)$ & \\
\hline $25-29$ & 501 & $5.6(3.7$ to 8.5$)$ & & $1.7(0.8$ to 3.3$)$ & \\
\hline $30-35$ & 583 & 6.6 (4.5 to 9.6$)$ & 0.39 & $1.2(0.5$ to 2.8$)$ & $<0.001$ \\
\hline \multicolumn{6}{|c|}{$3+$ partners past year } \\
\hline Yes & 445 & $10.6(7.6$ to 14.6$)$ & & 8.2 (5.5 to 12.0$)$ & \\
\hline No & 1674 & $6.6(5.1$ to 8.4$)$ & 0.02 & 2.7 (1.8 to 4.2$)$ & $<0.001$ \\
\hline \multicolumn{6}{|c|}{ New partner in past 3 months } \\
\hline Yes & 435 & 11.7 (8.2 to 16.4$)$ & & 9.3 , (6.3 to 13.6$)$ & \\
\hline No & 1657 & $6.3,(5.0$ to 8.1$)$ & 0.004 & 2.5 (1.6 to 3.8$)$ & $<0.001$ \\
\hline \multicolumn{6}{|l|}{ Previous STI } \\
\hline Yes & 503 & $12.8(9.6$ to 17.0$)$ & & 4.5 (2.7 to 7.2$)$ & \\
\hline No & 1372 & $6.7(5.2$ to 8.8$)$ & 0.001 & $4.3(3.0$ to 6.1$)$ & 0.91 \\
\hline
\end{tabular}

Results 2120 of 2936 respondents (72.2\%) provided specimens for STI testing. The prevalence of TV was $7.5 \%$ (95\% CI $6.0 \%$ to $9.0 \%)$ and was significantly higher among women $(11.8 \%)$ than men $(2.9 \% ; \mathrm{PR}=4.0$, $95 \%$ CI $2.2 \%$ to $7.4 \%$ ). Among Black females, the estimated prevalence was $16.1 \%$ (95\% CI 1.0\% to 19.8). Levels of TV infection ranged from $7.3 \%$ (95\% CI $4.7 \%$ to 11.2$)$ among $15-19$ year olds to $10.6 \%(95 \% \mathrm{CI}$ $7.6 \%$ to 14.7$)$ among those aged $20-24$ years and $6.6 \%(95 \%$ CI $4.5 \%$ to 9.6) among $30-35$ year olds ( $p=0.39$ for linear trend). Infection with $T$ vaginalis was more common than infection with $C$ trachomatis $3.9 \%$, $95 \%$ CI $2.7 \%$ to $5.0 \%$; $<<0.001)$. Unlike TV, CT did not vary by gender (women $4.5 \%$, men $3.4 \%, \mathrm{p}=0.35$ ) and infection prevalence was significantly higher among those $<25$ years of age ( $p<0.001$ for trend). Concomitant TV infection was detected in $23.5 \%$ of respondents with CT ( $\mathrm{PR}=3.7,95 \%$ CI $1.9 \%$ to 7.7$)$. Both TV and CT were associated with reporting of three or more partners in the past year and a new partner in the past 3 months. TV infection, but not CT, was associated with a previous STI diagnosis ( $\mathrm{PR}=1.9,95 \% \mathrm{CI} 1.3 \%$ to $2.8 \%$ ) see Abstract O1-S05.04 table 1.

Conclusions: Undetected $T$ vaginalis is common among young adults in Baltimore, particularly among women. Nearly one-fourth of respondents with chlamydial infection also tested positive for TV. Unlike chlamydial infection, the prevalence of TV was consistently high across all age groups. Our results provide strong support for routine screening for TV in conjunction with CT in populations at elevated risk of infection.

\section{1-S05.05 ASSOCIATION BETWEEN TRICHOMONAS VAGINALIS AND VAGINAL BACTERIAL COMMUNITY COMPOSITION AMONG ASYMPTOMATIC REPRODUCTIVE-AGE WOMEN IN THE USA}

doi:10.1136/sextrans-2011-050109.29

${ }^{1} \mathrm{R}$ Brotman, ${ }^{1} \mathrm{~L} \mathrm{~L}$ Jones, ${ }^{1} \mathrm{~J}$ Sakamoto, ${ }^{1} \mathrm{P}$ Gajer, ${ }^{2} \mathrm{~K}$ Ault, ${ }^{1} \mathrm{~L}$ Peralta, ${ }^{3} \mathrm{~L}$ Forney,

${ }^{3} \mathrm{Z}$ Abdo, 'J Ravel. 'University of Maryland, School of Medicine, Baltimore, USA; ${ }^{2}$ Emory University, School of Medicine, USA; ${ }^{3}$ University of Idaho, USA

Background Vaginal bacterial communities are thought to prevent infection by sexually transmitted organisms. Prior work 